Loganathan D

Satish Kumar $S$

Ramadoss $R$

https://doi.org/10.21278/TOF.44108

ISSN 1333-1124

eISSN 1849-1391

\title{
GREY RELATIONAL ANALYSIS-BASED OPTIMISATION OF INPUT PARAMETERS OF INCREMENTAL FORMING PROCESS APPLIED TO THE AA6061 ALLOY
}

\begin{abstract}
Summary
Incremental forming is mainly based on the deformation occurring locally on sheet metal. A hemispherical head tool deforms the sheet metal progressively, and its path is controlled by means of a CNC machine. Even though the process is a time-consuming one, the cost reduction connected with punches and dies makes this process attractive for rapid prototyping. In single point incremental forming, the quality of formability mainly depends on the forming parameters and the tool path generated. In this study, cone-shaped components were formed from AA6061 alloy sheets with a thickness of $1.15 \mathrm{~mm}$. Factors, such as feed rate, spindle speed, and step depth are considered as input parameters to determine the output response in terms of surface roughness and wall thickness. Taguchi's technique was used for conducting the experiments with the smallest number of repetitions to evaluate the output. Grey relational analysis was introduced to determine the optimal forming parameters with respect to the output response. The experiments conducted with the optimised parameters show a minimal deviation of $0.15 \%$ in the grade value compared to the predicted grade which is acceptable.
\end{abstract}

Key words: $\quad$ Incremental forming, Grey relational analysis, Surface roughness, Wall thickness

\section{Introduction}

In the last few years, efforts have been put in manufacturing industries to reduce the lead time and the manufacturing cost. Hence, there is a growing need for rapid prototyping of components before they come into use. Due to this trend, attention has been focused on new advanced and flexible technologies for rapid conversion of raw materials into a prototype. Single Point Incremental Forming (SPIF) is a process that can be applied to low volume and high-end design diversity products in manufacturing industries. This process is mainly adopted in industries because dimensions of components can be easily modified. The tool motion on the sheet metal produces friction between the tool tip and the sheet surface, by which the forming occurs. This friction enhances the poor surface finish of the finished product. This leads to the failure of the product at an earlier stage and also spoils the aesthetic 
appearance of the product in the final stage. Baruah et al. used Grey Relational Analysis (GRA) to study the effect of the input parameters in the SPIF process and found that lubrication is the main factor contributing to lowered surface roughness [1]. The major failure of the component occurs mainly due to the input process parameters even though the friction can be minimised by applying lubricant between the tool and the sheet metal while processing. Park et al. studied the effect of the process parameters as an outcome of the maximum formability [2]. Kim et al. conducted a series of experiments to investigate the effect of the input parameters (tool type, tool diameter, tool feed) through FEM [3]. Xu et al. analysed the effect of spring back through the Response Surface Methodology (RSM) during sheet metal forming [4]. Ambrogio et al. presented the effect of the input parameters (punch diameter, step depth, thickness of the sheet, wall angle, and total depth) by means of the Design of Experiments (DOE) and analysed the surface roughness of the AA1050 alloy sheet and the forming forces applied on it [5]. Ambrogio, Filice, and Manco, studied the variation in thickness by modifying the tool trajectory in SPIF [6]. Durante et al. studied the effect of the spindle speed on the surface roughness and geometric accuracy as the output responses [7]. Hagan et al. investigated the effect of input parameters on the surface roughness and found that the feed rate plays a vital role in the determination of surface roughness [8]. Mugendiran et al. carried out a study on the effect of the input parameters of SPIF on an aluminium alloy, using RSM; in the study, the surface roughness and thickness distribution were concerned as output responses [9]. Lakshminarayanan conducted tests for multiobjective optimisation of friction stir welded joints to obtain the optimum welding conditions considering the rotational speed, shoulder diameter, and welding speed [10]. Shanjeevi et al. conducted a study to determine the optimal welding parameters through multi-objective optimisation by using the weighted sum method on dissimilar friction welded joints [11]. Therefore, there is a need to optimise the input parameters before components are manufactured. Optimisation techniques should be implemented to minimize the required number of experiments to determine the optimum process parameters. Due to the complexity of the forming process, multi-objective optimisation is to be considered for a better response. Design of experiment is found to be an effective tool to define the relationship between the input process parameters and the output responses. Many researchers used different theories and approaches to study and optimise the process parameters to obtain an optimal solution to their multi-response problems. These methods are reliable; they save manufacturing time and reduce operational costs. The Taguchi Orthogonal Array (OA) along with the GRA was found to be one of the best tools to obtain accurate and reliable information. In this study, the optimisation of input parameters for SPIF was carried using the Taguchi OA-GRA method. Experiments were conducted for the L9 orthogonal array with the feed rate, spindle speed, and step depth as input parameters, each at three different levels. The effects of the input parameters and their interaction were studied.

\section{Materials and Methodology}

\subsection{Materials}

Cold rolled AA6061-T4 with a thickness of $1.15 \mathrm{~mm}$ was used in this analysis; its chemical composition determined through the chemical spectral analysis is given in Table1. In order to gain special advantages over ordinary room temperature sheet forming, an annealing process is carried out at $413^{\circ} \mathrm{C}$ for a soaking time of about 2 hours and 30 minutes, and then furnace cooling is allowed. This process refines the grain structure of the material. Thus, the ductility of the material is increased. The forming tool with a hemispherical tip is made of high speed steel, hardened to $64 \mathrm{HRC}$. 
Table 1 Chemical composition of AA6061 in the percentage of weight

\begin{tabular}{|c|c|c|c|c|c|c|c|c|}
\hline Element & $\mathrm{Mg}$ & $\mathrm{Si}$ & $\mathrm{Cu}$ & $\mathrm{Mn}$ & $\mathrm{Fe}$ & $\mathrm{Cr}$ & $\mathrm{Zn}$ & $\mathrm{Al}$ \\
\hline Observed & 0.94 & 0.71 & 0.3 & 0.098 & 0.47 & 0.19 & 0.13 & Bal. \\
\hline Nominal & $0.8-1.2$ & $0.4-0.8$ & $0.15-0.4$ & $0.15 \mathrm{max}$ & $0.7 \mathrm{max}$ & $0.04-0.35$ & $0.25 \mathrm{max}$ & Bal. \\
\hline
\end{tabular}

\subsection{Taguchi Approach}

The Taguchi method-based optimisation is one of powerful optimisation techniques that provide better optimal solutions with a reduced number of experiments. The input parameters are the tool feed $(\mathrm{V})$, spindle speed $(\mathrm{N})$, and step depth $(\mathrm{Z})$. The different levels of factors are given in Table 2.

Table 2 Controllable factors and their levels

\begin{tabular}{|l|c|c|c|c|c|}
\hline Description & Factor & Unit & Level 1 & Level 2 & Level 3 \\
\hline Spindle Speed (A) & $\mathrm{N}$ & $\mathrm{rpm}$ & 2,000 & 2,250 & 2,500 \\
\hline Tool Feed (B) & $\mathrm{V}$ & $\mathrm{mm} / \mathrm{min} \square$ & 400 & 500 & 600 \\
\hline Step Depth (C) & $\mathrm{Z}$ & $\mathrm{mm}$ & 0.5 & 0.75 & 1 \\
\hline
\end{tabular}

Using orthogonal arrays as a mathematical tool, Taguchi's method determines the minimum number of experiments to study a large number of variables. In their study, Muthuramalingam et al. tried to determine the minimum number of experiments required to be conducted based on Taguchi's method [12]. Choosing the correct orthogonal array for the experiment design is more important than the number of experiments and it depends on the control factors and the output responses. The relation between the input parameters and the chosen level mainly depends on the number of Degrees of Freedom (DOF) and is given by Equation 1.

$$
\text { Minimum number of DOF }=[(\mathrm{L}-1) \times \mathrm{P}]+1=[(3-1) \times 3]+1
$$

where ' $\mathrm{L}$ ' is the total number of levels and ' $\mathrm{P}$ ' is the total number of input parameters. The minimum required number of experiments should be greater than the number of degrees of freedom; hence, $\mathrm{L}_{9}$ orthogonal array has been chosen in order to assess the effect of each controllable factor on multiple outputs. The array requires nine experiments for a combination of three controllable factors at three levels. The sequence of tests to be followed is given in Table 3.

Table 3 Sequence of tests as per L9 orthogonal array

\begin{tabular}{|c|c|c|c|}
\hline Trial & $\begin{array}{l}\text { Spindle Speed } \\
\text { N/ (rpm) }\end{array}$ & $\begin{array}{l}\text { Tool Feed } \\
\text { V/ }(\mathrm{mm} / \mathrm{min})\end{array}$ & $\begin{array}{l}\text { Step Depth } \\
\text { Z / (mm) }\end{array}$ \\
\hline 1 & 2,000 & 400 & 0.5 \\
\hline 2 & 2,000 & 500 & 0.75 \\
\hline 3 & 2,000 & 600 & 1 \\
\hline 4 & 2,250 & 400 & 0.75 \\
\hline 5 & 2,250 & 500 & 1 \\
\hline 6 & 2,250 & 600 & 0.5 \\
\hline 7 & 2,500 & 400 & 1 \\
\hline 8 & 2,500 & 500 & 0.5 \\
\hline 9 & 2,500 & 600 & 0.75 \\
\hline
\end{tabular}


Performance characteristics of the input parameters used for studying the outputs in the Taguchi method fall into three categories: Larger-the-Better, Smaller-the-Better and Nominalthe-Better [Sreenivasan Konganapuram Sundararajan \& Satish Kumar Shanmugam] [13]. The equationused to obtain the Signal-to-Noise $(\mathrm{S} / \mathrm{N})$ ratios is given below.

The condition for the Smaller-the-Better is

$$
S / N=-10 \log \left(\frac{1}{n} \sum_{i=1}^{n} y_{i}^{2}\right)
$$

For the Larger-the-Better it is

$$
S / N=-10 \log \left(\frac{1}{n} \sum_{i=1}^{n} \frac{1}{y_{i}^{2}}\right)
$$

For the Nominal-the-Better it is

$$
S / N=10 \log \left(\frac{\bar{y}}{S_{y}^{2}}\right)
$$

\subsection{Grey Relational Analysis (GRA)}

GRA is a method in which the grey system theory is adopted to solve the problems with multiple outputs by analysing relationships. The main aim of this analysis is to create better relationships between the selected input parameters in a quantitative and a qualitative way and to find how they influence the surface roughness and wall angle in SPIF. In the grey relational analysis, the first experiments were normalised and the Grey Relational Coefficient (GRC) was calculated to develop a relationship between the required and the actual experimental data. Next, the Grey Relational Grade (GRG) was calculated by means of averaging the GRC with respect to each output response [Rajesh Prohit et al.] [14]. Thus, a hard multiple output response can be transformed into the optimisation of a single relational grade. The sequence with the highest GRG gives the optimum value of the factor [Firojkhan et al.] [15].

For normalising the values, the smaller-the-better is applied wherever the output response is to be minimum (Eq. 2) and wherever the output response is to be maximum, the larger-the-better is applied (Eq. 3). In this study, the smaller-the-better is considered to minimise the surface roughness; it is given as

$$
x_{i}(k)=\frac{\max y_{i}(k)-y_{i}(k)}{\max y_{i}(k)-\min y_{i}(k)}
$$

To increase the wall thickness, the larger-the-better is selected and expressed as

$$
x_{i}(k)=\frac{y_{i}(k)-\min y_{i}(k)}{\max y_{i}(k)-\min y_{i}(k)}
$$

where $\min y_{i}(k)$ is the least value of $y_{i}(k)$ for the $k^{\text {th }}$ response and max $y_{i}(k)$ is the maximum value of $y_{i}(k)$ for the $k^{\text {th }}$ response. The GRA is to show the relational degree between the defined sequences $x_{\mathrm{o}}(k)$ and $x_{i}(k), i=1,2, . ., 9 ; k=1,2,3$. The GRC $\xi_{\mathrm{i}}(k)$ can be obtained as

$$
\xi_{i}(k)=\frac{\Delta_{\min }+s \Delta_{\max }}{\Delta_{o i}(k)-s \Delta_{\max }}
$$


where $\Delta_{o i}(k)=\left\|\mathrm{x}_{o}(k)-\mathrm{x}_{i}(k)\right\|$ is the mean of absolute value between $x_{o}(k)$ and $x_{i}(k)$; the distinguishing coefficient is (0 to 1$) ; \Delta_{\min }$ and $\Delta_{\max }$ are the minimum and the maximum value of $\Delta_{\text {oi }}$. After averaging the GRCs, the relational grade ' $Y_{i}$ ' can be obtained as

$$
Y_{i}=\frac{1}{n} \sum_{k=1}^{n} \xi_{i}(k)
$$

where $n$ is the level of output responses. The larger the value of relational grade, the stronger is the relational degree within the reference sequence $x_{o}(k)$ and the given sequence $x_{i}(k)$, i.e. it is closest to the optimal value. In this study, the surface roughness obtained after forming carried out by the SPIF process is to be minimum and the wall thickness is to be maximum [Lu et al.][16]. In order to obtain such an output response, both the smaller-the-better and the larger-the-better equations (Equations 2 and 3) are selected.

\subsection{Methodology}

The experiments were conducted using a computer controlled milling machine. The fixture shown in Fig. 1 has a clamping plate and a backing plate to rigidly hold the sheet metal. A squarework sheet of $170 \mathrm{~mm} \times 170 \mathrm{~mm}$ having a working area of $115 \mathrm{~mm} \times 115 \mathrm{~mm}$ was used in this study.

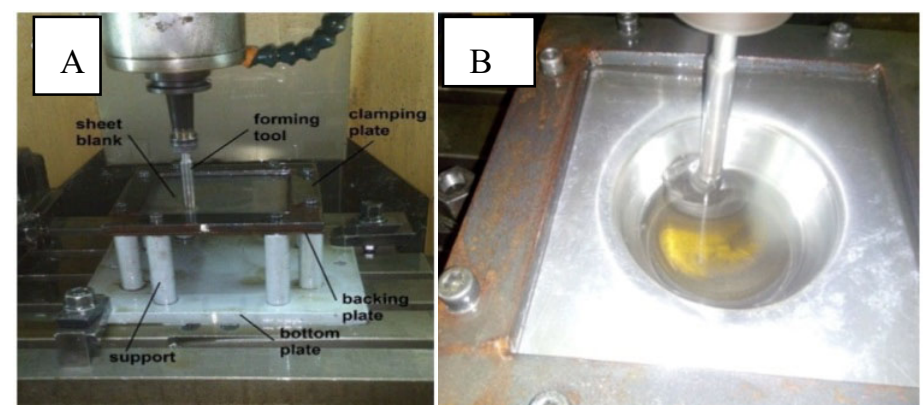

Fig. 1 (A) Fixture used in SPIF and (B) in the process with lubrication oil

A hemispherical-tip tool with $12 \mathrm{~mm}$ in diameter, made of high speed steel, was used. The tool path used for forming is a spiral shaped one as shown in Fig.2; the tool path has a combination of all three directions of forming. During forming, the SAE $20 \mathrm{w}-40$ oil was used as a lubricant between the contact surfaces. A constant wall angle of $65^{\circ}$ was chosen in this study. The tool path for this process was generated from the CAD file using the MASTERCAM software.

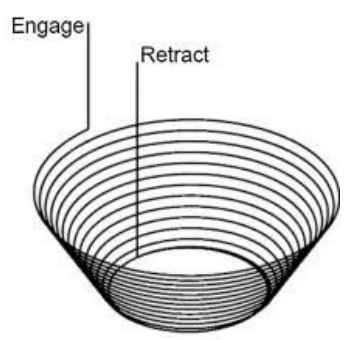

Fig. 2 Trajectory of the tool

\section{Results and Discussion}

Figure 3 shows a component designed using the CAD software and the final component formed by SPIF. Figure 4 shows the formed components processed using the $\mathrm{L}_{9}$ orthogonal array at different levels of process parameters listed in Table 3. 


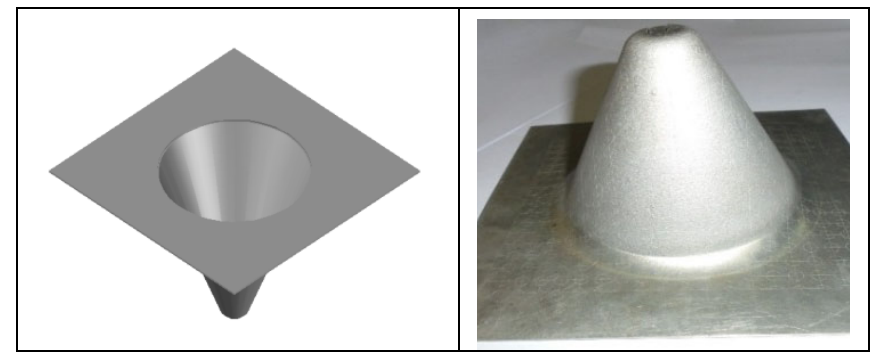

Fig. 3 Designed component and finished component

In order to analyse the thinning and surface roughness and to maintain the accuracy, a small strip of sheet metal was removed from the formed part using a wire EDM machine, as shown in Fig.5. The removed strip was checked for its thickness distribution over the formed area at three different sections and the averages of these three regions were taken for analysis.

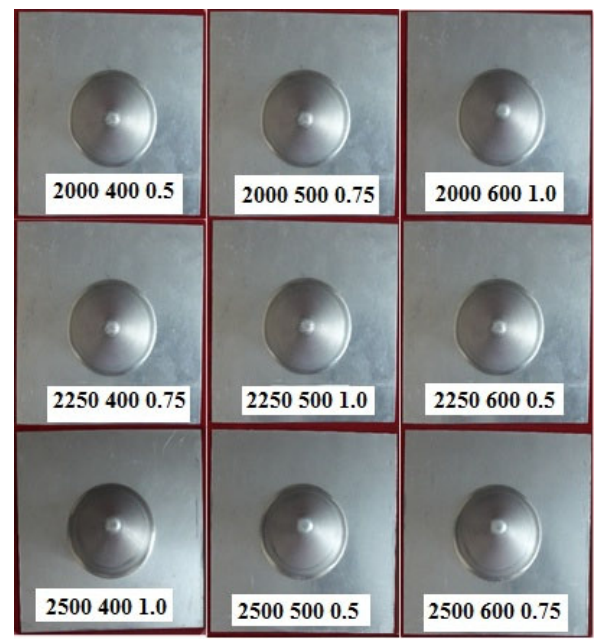

Fig. 4 Components formed as per L9 orthogonal array

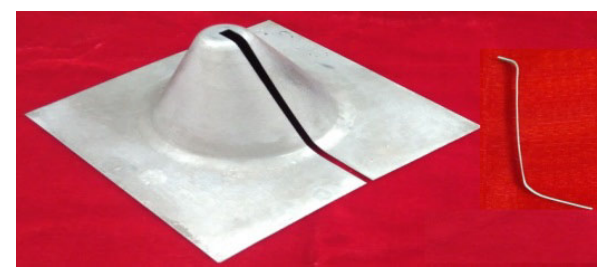

Fig. 5 A strip cut from the formed specimen to measure thickness distribution

\subsection{Micro-structural observation}

Figure 6 shows the thickness profile of the experimental output component. Four regions of the product, the holding region, the bending region close to the blank holder, the middle region, and the bottom region were considered in the micro-structural analysis.

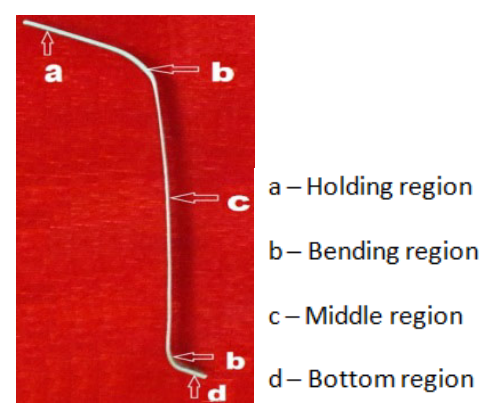

Fig. 6 Thickness profile of the formed area 
The phases of $\mathrm{Mg}_{2} \mathrm{Si}$ and $\mathrm{MgAl}_{2}$ in the aluminium alloy have homogenised grain formations which are evenly distributed. In the holding region (Fig.7 (a)), the grain orientation is shown in the longitudinal direction of rolling. In the bending region (Fig.7 (b)), at the first stress point in incremental forming one can observe the formation of curved flow lines in the direction of the process. In addition, the grains are elongated in the direction of depth. The particles have been fragmented due to the stress and the spin of the tool. The middle region (Fig.7 (c)) shows the thinned centre section of the forming process with completely elongated grains of the eutectic particles and the grains which have come closer to the center. In the bottom region (Fig.7 (d)), the grain orientation is similar to that in the holding region with the longitudinal direction of rolling formations.

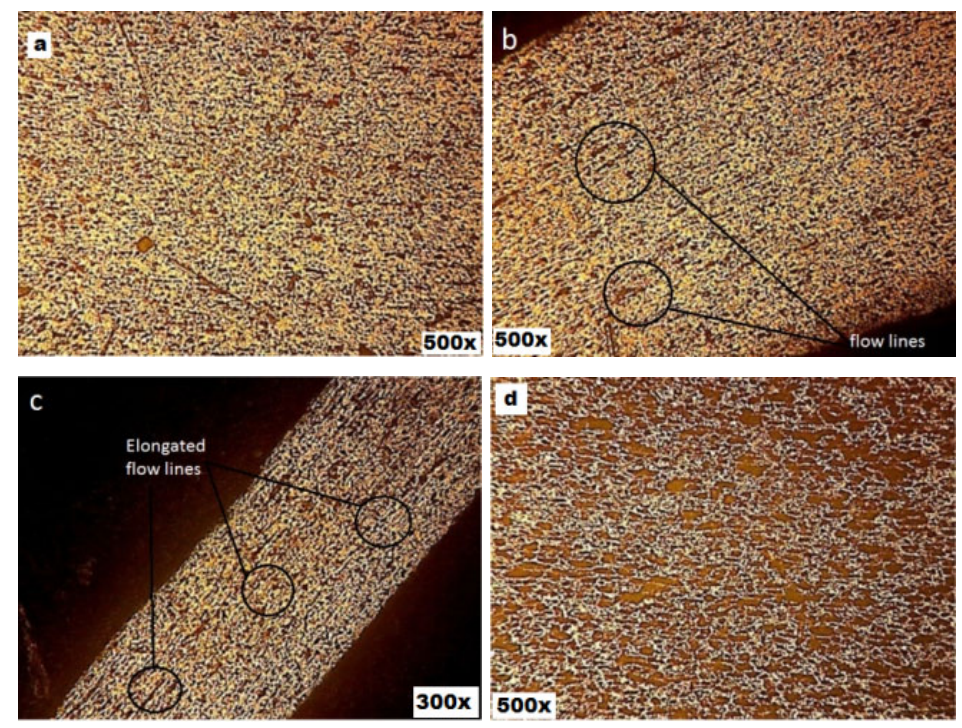

Fig. 7 Micro-structural analysis of the formed component with different regions:

(a) Holding, (b) Bending, (c) Middle, and (d) Bottom

\subsection{Prediction of the optimal parameter by means of GRA}

Based on the experimental outputs, the optimal process parameters for the SPIF of AA6061 were analysed. In general, the required wall thickness is to be maximum and the surface roughness obtained minimum. The value of the $\mathrm{S} / \mathrm{N}$ ratio was then calculated using equations 2 and 3 under the smaller-the-better condition for surface roughness and the largerthe-better for wall thickness [Srinivas et al.] [17]; the calculated values are listed in Table 4. Using equations 5 and 6 , the normalised $\mathrm{S} / \mathrm{N}$ ratio values are calculated for surface roughness (Ra) and wall thickness (WT). The quality loss values (GRA) for all the trials and responses were calculated, as shown in Table 5. Values of the grey rational coefficient were computed for Ra and WT by assuming that the distinguishing coefficient is 0.5 . The grey grade values are computed by averaging the GRCs of Ra and WT (Eq. 8). Now, the grey grade is similar to the multi-response performance index, which can be treated as a single response problem and can be analysed to predict the optimum levels of the input factors. Based on the results shown in Table 6 , the best combination was chosen as $A_{1}, B_{1}$, and $C_{2}$. This gives the maximum wall thickness and the minimum surface roughness. This combination indicates that the impact of the spindle speed and feed rate increases the formability of the sheet metal. Also, the step depth of cut plays a vital role in wall thickness. The surface roughness was mainly caused by the development of frictional forces during the metal-to-metal contact at high spindle speed and feed rate. This can be minimised by optimum process parameters and proved by the experiment no. 1 values. 
Table 4 Output responses and their $\mathrm{S} / \mathrm{N}$ ratios

\begin{tabular}{|c|c|c|c|c|}
\hline \multirow{2}{*}{$\begin{array}{c}\text { Exp. } \\
\text { no. }\end{array}$} & \multirow{2}{*}{$\begin{array}{c}\text { Surface } \\
\text { Roughness Ra }\end{array}$} & Wall Thickness & \multicolumn{2}{|c|}{ S/N ratio } \\
\cline { 4 - 5 } & $/(\mu \mathrm{m})$ & WT $/(\mathrm{mm})$ & $\mathrm{Ra}$ & $\mathrm{WT}$ \\
\hline 1 & 1.037 & 0.615 & -0.315575130 & -4.222497684 \\
\hline 2 & 1.161 & 0.597 & -1.296644395 & -4.480513377 \\
\hline 3 & 1.431 & 0.543 & -3.112792675 & -5.304003408 \\
\hline 4 & 1.07 & 0.592 & -0.587675554 & -4.553565866 \\
\hline 5 & 1.223 & 0.551 & -1.748529141 & -5.176968023 \\
\hline 6 & 1.436 & 0.525 & -3.143088798 & -5.596813932 \\
\hline 7 & 1.137 & 0.586 & -1.115209294 & -4.642047680 \\
\hline 8 & 1.27 & 0.542 & -2.076074419 & -5.320014269 \\
\hline 9 & 1.697 & 0.538 & -4.593636846 & -5.384354487 \\
\hline
\end{tabular}

Table $5 \mathrm{~S} / \mathrm{N}$ ratios (normalised) of output responses and the respective GRC values

\begin{tabular}{|c|c|c|c|c|c|c|c|}
\hline \multirow{2}{*}{$\begin{array}{c}\text { Exp. } \\
\text { no. }\end{array}$} & \multicolumn{2}{|c|}{$\begin{array}{l}\text { Normalised } \\
\mathrm{S} / \mathrm{N} \text { ratio }\end{array}$} & \multicolumn{2}{|c|}{$\begin{array}{l}\text { Quality loss } \\
\text { values (GRA) }\end{array}$} & \multicolumn{2}{|c|}{$\begin{array}{c}\text { Grey Relational } \\
\text { Coefficient }\end{array}$} & \multirow{2}{*}{$\begin{array}{c}\text { Grey } \\
\text { Relational } \\
\text { Grade }\end{array}$} \\
\hline & $\mathrm{Ra}$ & WT & $\mathrm{Ra}$ & WT & $\mathrm{Ra}$ & WT & \\
\hline 1 & 0.000 & 1.000 & 1.000 & 0.000 & 0.333 & 1.000 & 0.666 \\
\hline 2 & 0.229 & 0.812 & 0.771 & 0.188 & 0.393 & 0.727 & 0.560 \\
\hline 3 & 0.654 & 0.213 & 0.346 & 0.787 & 0.591 & 0.389 & 0.490 \\
\hline 4 & 0.064 & 0.759 & 0.936 & 0.241 & 0.348 & 0.675 & 0.511 \\
\hline 5 & 0.335 & 0.305 & 0.665 & 0.695 & 0.429 & 0.418 & 0.424 \\
\hline 6 & 0.661 & 0.000 & 0.339 & 1.000 & 0.596 & 0.333 & 0.465 \\
\hline 7 & 0.187 & 0.695 & 0.813 & 0.305 & 0.381 & 0.621 & 0.501 \\
\hline 8 & 0.412 & 0.201 & 0.588 & 0.799 & 0.459 & 0.385 & 0.422 \\
\hline 9 & 1.000 & 0.155 & 0.000 & 0.845 & 1.000 & 0.372 & 0.686 \\
\hline
\end{tabular}

Figure 8 shows the surface response plot that indicates the variation in the response to the experiment number, the surface roughness, and the wall thickness output. Trial 1 has a higher wall thickness value and lower surface roughness.

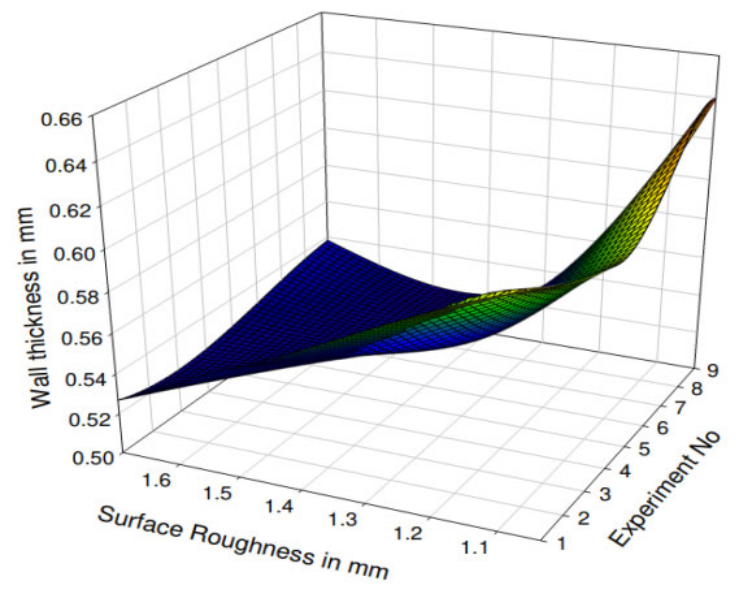

Fig. 8 Surface response plot of the output values 
Table 6 Output values of GRG

\begin{tabular}{|l|c|c|c|c|c|}
\hline Level & 1 & 2 & 3 & Delta & Rank \\
\hline Spindle Speed & $\mathbf{0 . 5 7 2 3}$ & 0.466 & 0.5362 & 0.1063 & 2 \\
\hline Tool Feed & $\mathbf{0 . 5 5 9 5}$ & 0.4687 & 0.5467 & 0.0904 & 3 \\
\hline Step Depth & 0.5177 & $\mathbf{0 . 5 8 5 7}$ & 0.4714 & 0.1143 & 1 \\
\hline
\end{tabular}

Although the grade values were analysed, the best possible combination of input parameters was finalised by the prediction of GRG using the larger-the-better category. The GRG was calculated from the response (Table 6) with a higher grade in each individual level by using Eq. 9 shown below.

$$
\hat{\gamma}=\gamma_{m}+\sum_{i=1}^{q}\left(\bar{\gamma}_{i}-\gamma_{m}\right)
$$

The predicted optimal value of the grade was 0.667 , with the optimal $A_{1}, B_{1}$, and $C_{2}$ process parameter for SPIF. A test was carried out to validate the optimal parameter with the A1B1C2 combination for the measurement of surface roughness and wall thickness. The predicted value is closest to the experimental design of the grade value. The GRG value of 0.666 obtained in the experiment has a minimal deviation of $0.15 \%$ with respect to the predicted mean value of 0.667 , which is acceptable, as shown in Table 7 . In order to find the effect of the most influential factor among the three parameters, the Analysis of Variance (ANOVA) is considered. The step depth makes the most significant contribution to surface roughness and wall thickness which amounts to $28.09 \%$, followed by the spindle speed with $24.4 \%$, and the tool feed with $21.94 \%$, as listed in Table 8 .

Table 7 Response values of GRG

\begin{tabular}{|c|c|c|}
\hline \multirow{2}{*}{ Output Responses } & \multicolumn{2}{|c|}{ Optimal SPIF parameters } \\
\cline { 2 - 3 } & Prediction & Experiment \\
\cline { 2 - 3 } & $\mathrm{A}_{1} \mathrm{~B}_{1} \mathrm{C}_{2}$ & $\mathrm{~A}_{1} \mathrm{~B}_{1} \mathrm{C}_{1}$ \\
\hline Surface Roughness & & 1.037 \\
\hline Wall Thickness & & 0.615 \\
\hline Grey Relational Grade & 0.667 & 0.666 \\
\hline
\end{tabular}

Table 8 ANOVA results for the $\mathrm{S} / \mathrm{N}$ ratios

\begin{tabular}{|c|c|c|c|c|c|c|}
\hline Source & DF & SS & MS & F Value & P Value & $\begin{array}{l}\% \\
\text { Contribution }\end{array}$ \\
\hline Spindle Speed & 2 & 4.540 & 2.270 & 0.95 & 0.512 & 24.40 \\
\hline Tool Feed & 2 & 4.081 & 2.040 & 0.86 & 0.538 & 21.94 \\
\hline Step Depth & 2 & 5.226 & 2.613 & 1.10 & 0.476 & 28.09 \\
\hline Error & 2 & 4.755 & 2.377 & & & 25.56 \\
\hline Total & 8 & 18.601 & & & & \\
\hline
\end{tabular}


Figure 9 shows the response graph with plotted levels of process parameters and the mean GRG (response) [Pandey et al] [18]. The graph shows the impact of levels of process parameters on wall thickness and surface roughness. The highest response is obtained at a spindle speed of $2000 \mathrm{rpm}$ (level 1), a feed rate of $400 \mathrm{~mm} / \mathrm{min}$ (level 1), and a vertical step depth of $0.5 \mathrm{~mm}$ (level 1).

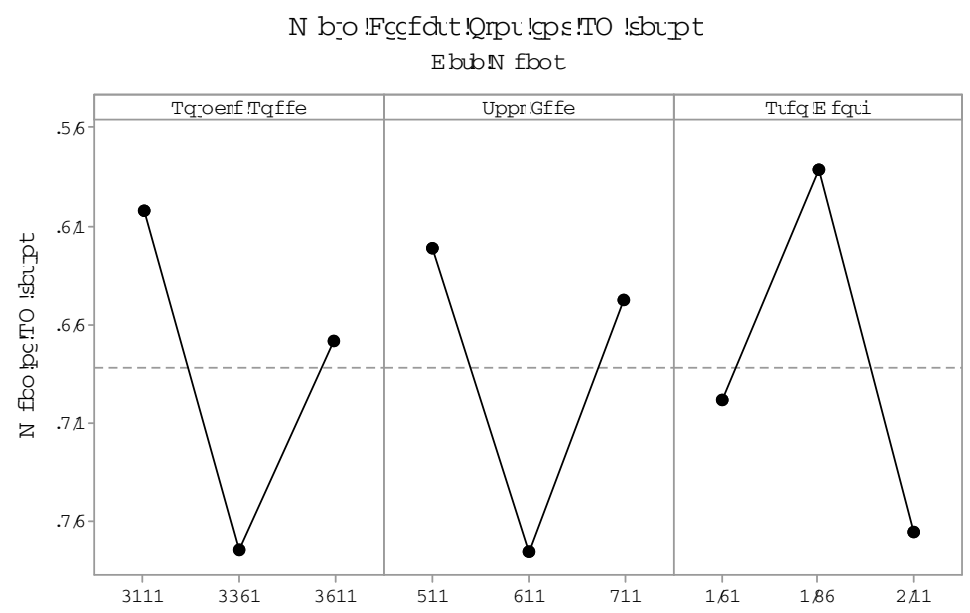

Fig. 9 Response graph showing the mean relational grades for three input parameters

\section{Conclusions}

An effort has been taken to study the forming performance characteristics of the single point incremental forming process. Spindle speed, tool feed, and step depth are considered as the input parameters, whereas surface roughness and wall thickness were considered as output responses. Taguchi's technique was used to determine the smallest number of experiments required to optimise the input parameters. Grey relational analysis of the conducted experiments was performed to study the contribution of parameters to the output response parameter in terms of minimising the surface roughness and maximising the wall thickness. The values of optimum input process parameters were found to be $0.5 \mathrm{~mm}$ for the vertical-step depth, $400 \mathrm{~mm} / \mathrm{min}$ for the tool feed with $2000 \mathrm{rpm}$ of the spindle speed. The accuracy of the prediction of optimal process parameters can still be improved by adopting a suitable multicriteria decision making system in the future.

\section{REFERENCES}

[1] Baruah A, Pandivelan C, Jeevanantham A.K, Optimization of AA5052 in incremental sheet forming using grey relational analysis, Measurements, 106,(2017), pp.95-100. https://doi.org/10.1016/j.measurement.2017.04.029

[2] Park JJ \& Kim YH, Fundamental studies on the incremental sheet metal forming techniques, Journal of Materials Processing and Technology, 140,(2000), pp. 447-453. https://doi.org/10.1016/s0924-0136(03)00768-4

[3] Kim Y.H, Park J.J, Effect of process parameters on formability in incremental forming of sheet metal, Journal of Materials Processing Technology, 130-131,(2002), pp. 42-46. https://doi.org/10.1016/s0924-0136(02)00788-4

[4] Xu W.L, Ma C.H, Li C.H, Feng W.J, Sensitive factors in spring back simulation for sheet metal forming, Journal of Materials Processing Technology, 151,(2004), pp. 217-225. https://doi.org/10.1016/j.jmatprotec.2004.04.044

[5] Ambrogio G, Costantino I, De Napoli L., Filice L., Fratini L, Muzzupappa M, Influence of some relevant process parameters on the dimensional accuracy in incremental forming; a numerical and experimental investigation, Journal of Materials Processing Technology, 153-154,(2004), pp. 501-507. https://doi.org/10.1016/j.jmatprotec.2004.04.139 
[6] Ambrogio G, Filice L, Manco G.L, Analysis of the thickness distribution varying tool trajectory in Single Point Incremental Forming, Journal of Engineering Manufacture Part B 225,(2011), pp. 348-356. https://doi.org/10.1177/09544054jem1958

[7] Durante M, Formisano A \&Langella, A Comparison between analytical and experimental roughness values of components created by incremental forming, Journal of materials processing technology, 210,(2010), pp. 1934-1941. https://doi.org/10.1016/j.jmatprotec.2010.07.006

[8] E Hagan and J Jeswiet, Analysis of surface roughness for parts formed by computer numerical controlled incremental forming, Proceedings of the Institution of Mechanical Engineers, Part B: Journal of Engineering Manufacture, 218,(2004),1307. https://doi.org/10.1243/0954405042323559

[9] Mugendiran V \& GnanavelbabuA, Comparison of plastic strains on AA5052 by single point incremental forming process using digital image processing, Journal of Mechanical Science and Technology, 31(6), (2017), pp. 2943-2949. https://doi.org/10.1007/s12206-017-0537-y

[10] Lakshminarayanan A.K., Enhancing the properties of friction stir welded stainless steel joints via multicriteria optimization, Archives of Civil and Mechanical Engineering, 16, (2016), pp.605-617. https://doi.org/10.1016/j.acme.2016.03.012

[11] C Shanjeevi, S Satish Kumar and P Sathiya, Multi - objective optimization of friction welding parameters in AISI 304L austenitic stainless steel and copper joints, Journal of Engineering Manufacture, 230, 3, (2016), 449-457. https://doi.org/10.1177/0954405414555590

[12] Muthuramalingam T, Mohan B, Taguchi-grey relational based multi response optimization of electrical process parameters in electrical discharge machining, Indian Journal of Engineering and Material Science, 20,(2013),pp. 471-475.

[13] Sreenivasan Konganapuram Sundararajan \& Satish Kumar Shanmugam, Multi-objective optimization of friction welding process parameters using grey relational analysis for joining aluminium metal matrix composite. Materials Science (Medziagotyra), 24,(2018), pp. 222-229. https://doi.org/10.5755/j01.ms.24.2.17725

[14] Rajesh Purohit, Rana R.S, Dwivedi R.K, Deepen Banoriya, Swadesh Kumar Singh, Optimization of electric discharge machining of M2 tool steel using grey relational analysis, Materials Today, 2 ,4-5, (2015), pp. 3387-3387. https://doi.org/10.1016/j.matpr.2015.07.312

[15] Firojkhan P, Hemanth G, Sonam G, Optimization for tribological properties of glass fibre-reinforced PTFE composites with grey relational analysis, Journal of Material,(2016), pp. 1-7.

[16] Lu B, Fang Y, Xu D.K, Chen J, Ou H, Moser, N.H, Cao J, Mechanism investigation of friction-related effects in single point incremental forming using a developed oblique roller-ball tool, International Journal of Machine Tool and Manufacture, 85,(2014), pp. 14-29. https://doi.org/10.1016/j.ijmachtools.2014.04.007

[17] Srinivas A, Venkatesh Y.D, Application of Taguchi method for optimization of process parameters in improving the surface roughness of lathe facing operation, International Refereed Journal of Engineering and Science, 11(3), (2012) pp. 13-19

[18] Rupesh Kumar Pandey, Panda S.S,. Optimization of bone drilling using Taguchi methodology coupled with fuzzy based desirability function approach, Journal of Intelligent Manufacturing, 26(6), (2015), pp. 1121-1129. https://doi.org/10.1007/s10845-013-0844-9 
Loganathan D, Satish Kumar S, Ramadoss R
Grey Relational Analysis-Based Optimisation of Input Parameters of Incremental Forming Process Applied to the AA6061 Alloy
Submitted: $\quad 11.6 .2019$

Accepted: $\quad 16.01 .2020$
Loganathan D

Research Scholar, Anna University, Chennai, 600 025, India.

Mechanical Engineering Department

Velammal Engineering College, Chennai, Tamilnadu, 600 066, India.

loganathand4@gmail.com

Dr. Satish Kumar Shunmugam, Professor, Mechanical Engineering Department Velammal Engineering College,Chennai, Tamilnadu, 600 066, India.

satish_shan@yahoo.com

Ramadoss R, Professor

Department of Mechanical Engineering,

Easwari Engineering College,

Chennai-603089, India.

drramdoss@gmail.com 